\title{
DIGNIDADE E UTOPIA NO PENSAMENTO DE ERNST BLOCH
}

\author{
Paulo Hahn ${ }^{1}$
}

\begin{abstract}
Resumo:
O presente artigo pretende recuperar aspectos históricos e filosóficos sobre o fundamento do princípio da dignidade humana e das utopias sociais no pensamento de Ernst Bloch, com ênfase na obra Naturrecht und menschliche Würde. No primeiro momento, pretende-se investigar a constatação e o princípio blochiano de que historicamente o direito natural teve como meta a dignidade da pessoa humana e as utopias sociais sempre tiveram como meta a felicidade humana neste mundo. Mas na práxis a felicidade (utopias sociais) e a dignidade (direito natural) marcharam separadamente por gerações. Sendo que Bloch sustenta uma relação dialética e complementar entre a dignidade e a felicidade. E por fim, no segundo momento, analisa-se a atualidade dos conceitos de não simultaneidade e multiverso cultural para uma melhor compreensão do Direito Natural e das Utopias Sociais com o intuito de ampliar e atualizar o horizonte temático, crítico e filosófico do Princípio da Dignidade Humana.
\end{abstract}

Palavras-chave: Utopias Sociais, Utopias Jurídicas, Direito Natural, Multiverso Cultural, Direitos Humanos, Dignidade.

\section{DIGNITY AND UTOPIA IN ERNST BLOCH'S THINKING}

\begin{abstract}
:
This article aims to recover historical and philosophical aspects about the foundation of the principle of human dignity and social utopias in Ernst Bloch's thought, with an emphasis on the work Naturrecht und menschliche Würde. In the first moment, we intend to investigate the finding and the Blochian principle that historically natural law had as its goal the dignity of the human person and social utopias have always had the goal of human happiness in this world. But in praxis, happiness (social utopias) and dignity (natural right) marched separately for generations. Bloch maintains a dialectical and complementary relationship between dignity and happiness. And finally, in the second moment, the currentness of the concepts of non-simultaneity and cultural multiverse is analyzed for a better understanding of Natural Law and Social Utopias in order to expand and update the thematic, critical and philosophical horizon of the Principle of Dignity Human.
\end{abstract}

Keywords: Social Utopias, Legal Utopias, Natural Law, Cultural Multiverse, Human Rights, Dignity.

1 Doutor em Filosofia pela Universidade de Bremen/Alemanha. Atualmente é professor Adjunto e Pesquisador da Universidade Federal da Fronteira Sul - UFFS - Campus Chapecó/SC, onde leciona na graduação de filosofia e no Programa de Pós-Graduação Stricto Sensu em Filosofia. Foi coordenador do Centro de Referência em Direitos Humanos e Igualdade Racial Marcelino Chiarello (CRDH) da UFFS. Autor, dentre outros livros, de "Ernst Bloch: die Dimension der Sozialutopie und ihr Einfluss im lateinamerikanischen Denken sowie die Konzepte Ungleichzeitigkeit und Multiversum als Grundbedingungen für das Verständnis und als Perspektive für einen interkulturellen Dialog”. E-mail: hahnpaulo@gmail.com. 


\section{DIGNIDADE E UTOPIA NO PENSAMENTO DE ERNST BLOCH}

Paulo Hahn

\section{1- Introdução}

Ernst Bloch é um dos poucos pensadores marxistas, que buscou recuperar traços da herança do Direito Natural. Em princípio, poderia parecer estranho ou até contraditório, que um pensador que permaneceu ao longo de seu percurso intelectual fiel a seu compromisso com a construção de uma sociedade socialista, seja defensor de uma ideia que, durante o século XX, tem sido sustentada fundamentalmente por pensadores conservadores e liberais. Porém a obra de Bloch Direito natural e dignidade humana, publicada em 1961, além de ser uma crítica ao sistema estabelecido, é também uma boa mostra de que é possível recuperar o caráter positivo do direito natural, inclusive como instrumento de crítica ao próprio direito existente e ao próprio marxismo.

O próprio Bloch reconhece que a obra em questão, pretende ser uma contribuição histórico-filosófica, trazendo uma profunda reflexão sobre o problema do que é justo e sobre o que ainda precisa ser feito para que todos possam efetivamente andar de passo erguido. Neste artigo queremos mostrar que Bloch sustenta uma relação dialética e complementar entre o direito natural (utopias jurídicas) e as utopias sociais. E por fim, trataremos dos conceitos de Não Simultaneidade e Multiverso Cultural enquanto ampliação e atualização do horizonte temático, crítico e filosófico do Princípio da Dignidade Humana.

Com duplo propósito, crítico e utópico, Bloch busca detalhar ou vincular a história das teorias emancipatórias do direito, com foco em cimentar e expandir o campo dos direitos humanos, inclusive para o marxismo (socialismo). O artigo tem como objetivo examinar esse aspecto do pensamento blochiano, mostrando sua relevância e atualidade.

Parte-se do princípio blochiano de que o direito natural tem como meta a dignidade humana e as utopias sociais a felicidade humana neste mundo. Felicidade e dignidade marcharam separadamente por gerações - e sua separação é a grande conquista do liberalismo. Essa relação dialética entre dignidade e felicidade permeia a estrutura não apenas do Direito Natural e Dignidade Humana, mas também do O Princípio Esperança. Há como que um fio condutor que perpassa nossa reflexão e que se caracteriza pelo seu duplo propósito: Primeiro pela sua postura crítica a todas as circunstancias nas quais o ser humano é negado em sua dignidade (renúncia, humilhação, escravidão, dependência, abandono), e reduzido à mercadoria, a capital humano e despida de qualquer valor jurídico e ético. Segundo pela sua

\begin{tabular}{|l|l|l|l|l|}
\hline Qevista 2 ialectus & Ano 10 & n. 21 & Janeiro - Abril 2021 & p. 176 - 188 \\
\hline
\end{tabular}




\section{DIGNIDADE E UTOPIA NO PENSAMENTO DE ERNST BLOCH}

Paulo Hahn

insistente busca da utopia ética, da defesa dos direitos humanos, da felicidade e da fundamentação de uma sociedade justa na qual o desenvolvimento pleno (digno) do indivíduo seja condição necessária para o desenvolvimento pleno da espécie. Trata-se de fundamentar a relevância do direito natural e das utopias sociais enquanto perspectiva crítica-utópica para os direitos humanos.

A dignidade é algo que pertence a todos os homens, mas é preciso que haja empenho em se criar condições nas quais ela possa efetivamente se desenvolver. Aqui o discurso sobre a dignidade adquire um conteúdo fortemente emancipatório. Destinatários da dignidade não são mais os indivíduos racionais conscientes e independentes, mas crianças, mulheres, anciões, povos e culturas, etc. $\mathrm{O}$ homem não é primeiramente animal rationale e nem animal morale, mas "animal com necessidades" (BECCHI, 2013, p. 32).

\section{2- Direito Natural e Dignidade Humana}

A obra $O$ direito natural e a dignidade humana (NM) consiste em duas partes: a primeira metade da obra trata da história do pensamento filosófico jurídico desde os sofistas até Hans Kelsen e Carl Schmitt. Nela contém uma releitura marxista e utópica das principais correntes que surgiram ao longo da história acerca da noção de direito natural. Para Bloch essas teorias - que no fundo podemos resumir em três: a antiga, a medieval tomista e do jusnaturalismo racionalista - representam a ideologia de uma classe social nascente que tenta subverter a ordem estabelecida ou da ideologia da classe dominante. O positivismo jurídico que aparece depois do jusnaturalismo moderno, seria o resultado do triunfo da classe burguesa, que, uma vez alcançada pela hegemonia com o apoio do direito natural racionalista, se havia despojado - como forma de consolidar sua dominação - de uma doutrina que conteria fatores revolucionários. Já a segunda metade discorre sobre abordagens de uma filosofia jurídica marxista, ou seja, trata de estabelecer a validez da ideia de direito natural dentro da visão marxista de homem. Primeiramente ele defende a preservação dos direitos humanos com base no direito natural, e em seguida segue com discussões sobre questões/perguntas/temas centrais do direito penal, direito constitucional e a relação entre direito e moralidade. Um capítulo final é dedicado especificamente à perspectiva metafísico-escatológica, a partir da qual a filosofia jurídica de Bloch é permeada como um todo. Bloch termina seu livro (NW) com um apêndice

\begin{tabular}{|l|l|l|l|l|}
\hline Qevista Dialectus & Ano 10 & n. 21 & Janeiro - Abril 2021 & p. 176 - 188 \\
\hline
\end{tabular}




\section{DIGNIDADE E UTOPIA NO PENSAMENTO DE ERNST BLOCH}

Paulo Hahn

dedicado ao jusnaturalista alemão, da época do iluminismo, Christian Thomasius - um intelectual alemão sem miséria.

O marxismo chamado ortodoxo entende o direito como uma superestrutura que representa um fator de dominação da classe opressora sobre a classe oprimida, ou seja, o direito objetiva os interesses da classe dominante. Sendo assim, o direito é apenas direito positivo, e o direito natural é algo inexistente. No entanto, nas últimas décadas alguns autores marxistas, tem mostrado um certo interesse pela ideia de direito natural e tentaram estabelecer uma possível ponte de união entre a teoria marxista e o direito natural. Essas tentativas poderíamos chamar de marxismo com rosto humano, na perspectiva de encontrar na teoria marxista um reconhecimento da dignidade do homem (HERVADA, 1984, p. 390).

O ideal político e emancipatório do Direito Natural é aceito, até certo ponto, pelos libertários e até mesmo pelos marxistas. Os Marxistas, que num passado recente, viam o Direito Natural como um mero instrumento superestrutural, voltado à manutenção do poder das elites, começaram a vê-lo diferente. O conceito clássico de Direito Natural foi submetido a uma severa reavaliação pelo filósofo marxista Ernst Bloch em seu influente livro Naturrecht und menschliche Würde. "Ernst Bloch, no entanto, na tarefa de reinterpretar a história do pensamento jurídico, salvará alguns sentidos utópicos do direito, que só se cumpririam numa nova dialética das relações sociais". (MARSCARO, 2008, p. 134).

A utopia social antecipa situações em que deixam de existir os explorados $e$ oprimidos, enquanto que o direito natural construiu situações em que deixam de existir os humilhados e ofendidos. O direito natural seria o que há de imutável ou invariável no homem ao longo da história e se realizaria na sociedade socialista sem classes. Esse imutável/invariável é o que Bloch chama de dignidade humana e que ele descreve com a frase de o passo erguido (aufrechter Gang, BLOCH, 1985, p. 257). Somente essa “intenção de passo erguido" seria o que de verdadeiro e invariável haveria na ideia de direito natural. Para Bloch, seguindo as teses marxistas, não há um ser genérico fixo no homem com qualidades estáticas, mas sim há uma transformação constante do homem, pois o homem é um produto das relações sociais do momento. O único componente que perpassa invariavelmente a história é a tendência para a desalienação fundamentada no princípio da dignidade humana (HERVADA, 1984, p. 390-391).

Esse direito natural somente poderá alcançar realização plena na sociedade sem classes. Assim, o direito natural subjetivo consistiria na tese marxista de cada um segundo sua

\begin{tabular}{|c|c|c|c|c|}
\hline Qevista Dialectus & Ano 10 & n. 21 & Janeiro - Abril 2021 & p. $176-188$ \\
\hline
\end{tabular}




\section{DIGNIDADE E UTOPIA NO PENSAMENTO DE ERNST BLOCH}

Paulo Hahn

capacidade, a cada um segundo sua necessidade. Já o direito natural objetivo se encontraria na solidariedade (BLOCH, 1985, p.252).

Nessa obra, Bloch interroga sobre o bom direito e sobre o direito e o estado como forma de regulação social. Ele faz um percurso histórico e filosófico sobre vários pensadores clássicos da filosofia do Direito, dando ênfase à expressão e à herança da Dignidade e Felicidade Humana. Existe uma conexão entre dignidade e necessidade, mas sempre dando uma ênfase à dimensão social da dignidade. A dignidade é algo que pertence a todos os homens, mas é preciso que haja empenho em se criar condições nas quais ela possa efetivamente se desenvolver (BECCHI, 2013, p 32). A “dignidade humana é impossivel sem se alcançar o fim das necessidades humanas, como a felicidade conveniente ao homem é impossivel sem o fim da submissão velha e nova" (BLOCH, 1985, p. 14).

Para Bloch, a tutela da dignidade humana vai além da "personalidade do homem" e implica a "solidariedade entre os homens" e toda a superação dos relacionamentos socioeconômicos que são um obstáculo a sua realização (MAIHOFER, 1968, p. 40-41). Em outras palavras, a dignidade humana não pode prescindir da satisfação das necessidades humanas concretas, pelas quais o Estado social e de Direito é convocado a se responsabilizar (BECCHI, 2013, p. 30).

A tese de Bloch novamente se faz presente e também necessária nas atuais discussões. Ele faz referência ao fato de que a dignidade humana não pode referir-se somente à pessoa abstrata enquanto sujeito jurídico, mas também ao indivíduo concreto, enquanto sujeito subordinado a relacionamentos socioeconômicos e culturais. O homem não é primeiramente animal rationale e nem animal morale, mas "animal com necessidades" (BECCHI, 2013, p. 32). E quanto mais a sociedade está apta para satisfazer essas necessidades, tanto mais se realiza nela a dignidade humana. Para Bloch, durante muito tempo o Direito natural tem representado a única forma de protestar frente às situações de dominação existentes, porém também houve falta de conteúdo concreto e com isso muitas vezes foi utilizado para legitimar a ordem estabelecida. Contudo, considera que, mesmo que o Direito natural tenha em alguns momentos históricos se convertido em uma ideologia, nele existe também uma "herança" que deverá ser reconhecida enquanto expressão de anseio de transformação social.

O imperativo categórico da utopia social (acabar com a exploração) e o imperativo categórico do direito natural e das utopias jurídicas (acabar com a humilhação), sustentam de

\begin{tabular}{|l|l|l|l|l|}
\hline Qovista Dialectus & Ano 10 & n. 21 & Janeiro - Abril 2021 & p. 176 - 188 \\
\hline
\end{tabular}




\section{DIGNIDADE E UTOPIA NO PENSAMENTO DE ERNST BLOCH}

Paulo Hahn

que não há dignidade humana sem eliminação da miséria, tampouco nenhuma felicidade verdadeiramente humana sem eliminação de toda servidão, tanto antiga como moderna (BLOCH, 1999 p. 234). Bloch descobre na tradição do Direito Natural e nas Utopias Sociais o traço humano historicamente variável, porém eterno, de resistir à dominação e à opressão e de imaginar e lutar por uma sociedade mais justa e feliz. Ambas (utopias sociais e direito natural) pertencem ao nobre poder da antecipação de algo melhor que ainda não há chegado a ser e tem suas raízes no reino da esperança.

$\mathrm{Na}$ atualidade, para os defensores de utopias jurídicas e sociais e de direitos humanos, o Estado de Direito é visto como uma ferramenta indispensável para evitar a discriminação, justiça social e toda forma de violência. Neste sentido, podemos afirmar, que o Estado de Direito, efetivamente será alcançado mediante uma verdadeira realização ou "verdadeira instituição dos direitos humanos" (BLOCH, 1985, p.13). Mas lembrando que para Bloch não existe democracia sem socialismo, e não existe socialismo sem democracia: "Keine Demokratie ohne Sozialismus, kein Sozialismus ohne Demokratie" (BLOCH, 1985, p. 232).

O Direito Natural e Dignidade Humana não é um novo tratado nem uma nova teoria do Direito natural; não é nem sequer uma história ao uso das teorias do jusnaturalismo, mas é uma interpretação desde um ponto de vista determinado de uma das correntes que intensamente tem influenciado nos destinos da humanidade ocidental. Por isso que a concepção do Direito natural sustentada por Bloch seja dificilmente equiparada com as demais versões que ao longo do século XX tenha existido sobre o jusnaturalismo.

Em Bloch, a forma de entender o Direito natural se deriva de sua própria concepção da filosofia e de sua determinação de situar o conceito de crítica e utopia no centro da realidade desde a perspectiva de um mundo aberto e de esperança. Sob esta ótica o Direito Natural é uma forma de consciência antecipadora que surge do âmbito desiderativo de um mundo melhor, da consciência utópica humana. Porque o autêntico Direito Natural, baseado em uma vontade racional libertada, postulava uma justiça conquistada pela luta e pela organização; não uma justiça vinda do alto, de decima para baixo, mas sim uma justiça ativa, uma justiça de debaixo para cima (BLOCH, 1985, p. 227), uma justiça vinda dos conflitos sociais e da luta por reconhecimento.

Esse caráter "aberto" da história é o que motiva Bloch. A categoria "possibilidade" tem um caráter dual: por um lado pode ser expressão das melhores aspirações da Humanidade

\begin{tabular}{|l|l|l|l|l|}
\hline Q & Ano 10 & n. 21 & Janeiro - Abril 2021 & p. $176-188$ \\
\hline
\end{tabular}




\section{DIGNIDADE E UTOPIA NO PENSAMENTO DE ERNST BLOCH}

Paulo Hahn

e, por outro lado, quando seu significado original é pervertido, pode servir como forma de dominação absoluta. Bloch é o filósofo da utopia, mas também destacou o caráter dual da utopia: utopia não é utopismo, esboço vazio de um projeto de sociedade. A utopia deve estar fundada, deve tornar-se utopia concreta, porque do contrário se converte em puro escapismo, que em último extremo serve ao fortalecimento da submissão do dado. O Direito natural é utopia jurídica, mas pode também ser uma ideologia legitimadora da injustiça presente. Tem sido as vezes expressão dos anseios de transformação social dos humilhados e ofendidos e também meio de consagração do domínio de classe.

Contudo, Bloch considera que, mesmo que o Direito natural tenha em alguns momentos históricos se convertido em uma ideologia, nele existe também uma "herança" que deverá ser reconhecida enquanto expressão de anseio de transformação social.

Bloch realiza um recorrido absolutamente heterodoxo pela história do direito natural, centrando-se naqueles autores e escolas que hão entendido ditos direitos como base da liberação humana e da revolução social.

A publicação do Direito natural e dignidade humana em 1961 ocorreu no mesmo período em que Bloch se transferiu de Leipzig à Tübingen, e também, no período em que ocorre a ruptura definitiva com a Alemanha Oriental, ou seja, com a DDR (Deutsche Demokratische Republik = RDA República Democrática Alemã), e com a política e a ideologia geral do "socialismo real". Em si, o livro não só contém uma crítica aos atropelos contra a justiça sob o sistema capitalista, mas também é um intento para desmascarar, como há indicado Arno Münster, "a falta de respeito pelos direitos humanos nos paises do socialismo realmente existente, que estavam tão orgulhosos de haver suprimido o capitalismo e a exploração do homem pelo homem, porém no concreto também infringem os direitos humanos". (MÜNSTER, 2004, p. 316).

Será a partir da análise histórica do direito natural que Bloch encontra a encarnação mais genuína deste desejo de justiça absoluta que não se contenta com um acomodamento dentro das circunstâncias vigentes; este animus rebelde revela o laço que une, para além de suas divergências inegáveis, o direito natural com as utopias sociais, como duas tradições insurgentes de cujo legado não poderia jamais desfazer-se o materialismo histórico.

$\mathrm{O}$ momento de florescimento das duas tradições não é coincidente: o direito natural alcança seu ponto alto nos séculos XVII e XVIII, enquanto que as utopias encontram seu ponto

\begin{tabular}{|c|c|c|c|c|}
\hline Q Rovista Dialectus & Ano 10 & n. 21 & Janeiro - Abril 2021 & p. $176-188$ \\
\hline
\end{tabular}




\title{
DIGNIDADE E UTOPIA NO PENSAMENTO DE ERNST BLOCH
}

Paulo Hahn

de culminação nos começos do século XIX - com Fourier, Owen e Saint-Simon -; mas os dois sonhos de uma vida social melhor não estão dissociados:

\begin{abstract}
As utopias sociais estão dirigidas principalmente à felicidade (Glück), ou pelo menos, à eliminação da necessidade e das circunstancias que mantém ou produzem aquela. As teorias jusnaturalistas, pelo contrário, como se viu claramente, estão dirigidas predominantemente à dignidade (Würde), aos direitos do homem, a garantias jurídicas de segurança ou liberdade humanas, como categorias de orgulho humano. E de acordo com isso, a utopia social está dirigida, sobretudo, à eliminação da miséria (Elends) humana, enquanto que o direito natural está dirigido, acima de tudo, à eliminação da humilhação (Erniedrigung) humana. A utopia social quer afastar tudo o que se opõe à eudemonia (felicidade) de todos, enquanto que o direito natural quer acabar com tudo o que se opõe à autonomia e a sua eunomia (boa lei) $(\mathrm{BLOCH}, 1985$, p. 234-235).
\end{abstract}

Bloch descobre na tradição do Direito Natural e nas Utopias Sociais o traço humano historicamente variável, porém eterno, de resistir à dominação e à opressão e de imaginar e lutar por uma sociedade na qual o homem vai andar de cabeça erguida.

Contudo, o propósito não é tanto realizar uma reconstrução histórica de um fenômeno do passado, mas destacar sua essencial atualidade; mais ainda, para sinalar que para a práxis política e para os direitos humanos, o direito natural e as utopias sociais não são somente antecedentes importantes, mas sim latências vivas que esperam e incluem demanda de realização. Aqui se põe de relevo a conexão entre as análises do direito natural e um dos temas que ocuparam a Bloch desde muito cedo: o problema da herança e da não simultaneidade dos tempos (HAHN, 2007, p. 139-149). Exibido em diversos contextos, mas, sobretudo na obra Erbschaft dieser Zeit (Herança desta época, 1933).

Disso segue para Bloch que "a coisa ainda não está decidida, ela se encontra em voga, está em suspenso", e isso significa que ainda existe esperança por um bom final, por mais poderosa que seja a ameaça da ruína. Nesse sentido esperança significa a recusa de se entregar à resignação e recusa também a terrível visão Weberiana de um cosmos econômico moderno, donde as condições técnicas e mecânicas determinam irresistivelmente o estilo de vida de toda a população, levando-lhes a uma especialização petrificada e vazia, culminando num processo de desumanização.

Bloch incorpora um conceito que é o de não-simultaneidade, para referir-se ao tempo da República de Weimar e o surgimento do fascismo na Alemanha. Ou seja, para Bloch,

\begin{tabular}{|l|l|l|l|l|}
\hline Qenista 2 Dialectus & Ano 10 & n. 21 & Janeiro - Abril 2021 & p. 176 - 188 \\
\hline
\end{tabular}




\section{DIGNIDADE E UTOPIA NO PENSAMENTO DE ERNST BLOCH}

Paulo Hahn

em um tempo concreto pode suceder que coexistem distintos momentos históricos, culturais e ao mesmo tempo em contradição.

\section{Não Simultaneidade e Multiverso Cultural enquanto Práxis e Luta por Reconhecimento e Dignidade Humana.}

Inicialmente convém introduzir aqui os conceitos de não-simultaneidade e consequentemente a trans-simultaneidade dos tempos. Estes nos remetem a conteúdos temporais, ao futuro e ao passado. Um esboço da ideia de "não-simultaneidade do simultâneo" aparece na obra de Ernst Bloch A herança deste tempo (1962).

Nesta obra Bloch explica que numa sociedade existem diversas classes sociais, cada uma com seu tempo particular. E, dentro das próprias classes, coexistem vários estratos sociais e, paralelamente, tempos latentes - míticos e arcaicos ou utópicos e antecipadores. Com isso Bloch distingue entre várias camadas de não-simultaneidade, quer dizer, que também coexistem não-simultaneidades no campo social, cultural, econômico e físico. Portanto, isto implica que diversos tempos podem atuar no presente, e que um mesmo nível de tempo pode ter distintos níveis de consciência e de condições. Assim por exemplo, uma consciência não-simultânea também pode tomar uma posição crítica e romper com o simultâneo, e antecipando novas perspectivas.

Partindo deste cenário, pretende-se, de forma resumida, expor a línea de desenvolvimento blochiano sobre o conceito de não-simultaneidade. Conforme Dietschy, referindo-se a obra Erbschaft dieser Zeit, poderíamos extrair os seguintes materiais heterogêneos: 1) A não-simultaneidade de estruturas mentais, de racionalidade, de níveis de consciência e de imaginação; 2) As estruturas de classe, que não podem ser reduzidas simplesmente a um esquema de duas classes ou classes antagônicas, e seus tempos sociais; 3) As tendências desiguais de desenvolvimento em esferas espacialmente restringidas, como por exemplo: na cidade e no campo, em regiões e nações, e no âmbito dos modos de produção; 4) As estruturas heterogêneas do tempo no âmbito político, legal e cultural; 5) Anacronismos, o arcaico e as formas de regressão no sujeito, a esfera do nível inconsciente. (DIETSCHY, 1988, p. 124-152).

\begin{tabular}{|l|l|l|l|l|}
\hline Q & Ano 10 & n. 21 & Janeiro - Abril 2021 & p. $176-188$ \\
\hline
\end{tabular}




\section{DIGNIDADE E UTOPIA NO PENSAMENTO DE ERNST BLOCH}

Paulo Hahn

Essa lógica de pensamento nos leva a perceber e entender o contraditório no processo universal e compreender conceitualmente a dinâmica da história. E por contradição Bloch entende a diferença entre o agora não realizado e o verdadeiro futuro impedido. $\mathrm{Na}$ verdade, Bloch parte de uma tríade conceitual: não-simultaneidade, simultaneidade e transsimultaneidade; e, com isso, postula o resgate e a transformação dialética do que merece ser herdado do passado, da não-simultaneidade.

É justamente neste sentido que Bloch faz uso do conceito de trans-simultaneidade dos tempos, aquilo que sobrepassa o presente, seria ao contrário, o lado positivo da nãosimultaneidade, algo que deveríamos herdar. A trans-simultaneidade seria o movimento progressivo, antecipador e utópico, aquele movimento que se adiantaria a condição histórica.

Dessa forma, já podemos entender de que para Bloch a categoria da nãosimultaneidade possui várias dimensões: por um lado, afirma o espírito utópico da humanidade e da cultura; e, por outro, afirma a descontinuidade no processo histórico. Com isso, Bloch reconhece o caráter plural do mundo global, ou seja, fala de um mundo com vidas, memórias, histórias, identidades e culturas diferentes, fala de um multiverso. Com este termo (multiverso), Bloch enfatiza a igualdade e a unidade substancial como também as possibilidades múltiplas de interconexão. Bloch vincula a problemática da cultura com a pergunta filosófica-social acerca das circunstâncias da vida e as relações de produção.

Uma definição mais precisa sobre a categoria blochiana de multiverso, aparece somente mais tarde, na obra de Introdução de Tübinger a Filosofia (1970), especificamente na quarta tese Diferenciação no conceito de progresso. Ali Bloch aplica o termo de nãosimultaneidade também ao conceito de Progresso e ao multiverso, e com isso introduz também a heterogenidade e multiplicidade histórica e cultural, a qual Bloch procura expressar e fundamentar com o termo Multiverso.

No lugar da unilinealidade requer-se um "multiversum" amplo, elástico, totalmente dinâmico; um contraponto contínuo e frequentemente enlaçado de vozes históricas. Desta maneira e para fazer justiça ao gigantesco material extraeuropeu, já não é possível trabalhar de modo unilineal, sem sinuosidades na série (ordem), sem uma complexa e nova variedade de tempo. Todo conteúdo da meta a que se refere o verdadeiro progresso e ao que conduz deve ser reconhecido igualmente de modo amplo e profundo de maneira que os diferentes povos, sociedades, culturas na terra - com toda a uniformidade de seus estados de desenvolvimento

\begin{tabular}{|c|c|c|c|c|}
\hline Qovista Dialectus & Ano 10 & n. 21 & Janeiro - Abril 2021 & p. $176-188$ \\
\hline
\end{tabular}




\section{DIGNIDADE E UTOPIA NO PENSAMENTO DE ERNST BLOCH}

Paulo Hahn

econômico e social e suas leis dialéticas - tenham lugar nele e para ele. Assim, pois, hão de se apresentar no marco de uma filosofia da história as culturas extraeuropéias existentes sem violação europeizante e nem sequer com uma nivelação de seus testemunhos específicos, como testemunhos da riqueza da natureza humana.

Essa questão ganha uma nova atualidade, se pensarmos na não-simultaneidade dos tempos, no multiverso cultural, na heterogeneidade, na diversidade e na multiplicidade enquanto aos espaços, as características, as memórias, os ritmos e as culturas. Com esses conceitos de Bloch e com os conteúdos que lhes são inerentes, se pode compreender e discutir hoje os problemas e as tendências da globalização, precisamente no sentido da necessidade de uma interculturalidade.

Bloch aproxima-se muito dos princípios da interculturalidade ao empregar o conceito de unidade e multiverso das nações, das identidades e das culturas - onde o particular e o universal sejam preservados. Com isso, ele não somente quis expor o pluralismo de diferentes maneiras de viver. Pois também compreendeu este pluralismo no seu aspecto temporal, contextual, global, unitário e intercultural. No fundo, o conceito de multiverso provoca a discussão sobre o tema da multi e da interculturalidade. Ou seja, apesar do multiverso - de caminhos e de culturas - nós temos uma história universal comum, ou seja, o multiculturalismo, o multiverso e a não-simultaneidade devem também estar unidos com o conceito de interculturalidade, alteridade, identidade e com o universal. Somente neste âmbito podemos pensar e discutir a cultura no sentido plural.

Esse cenário nos leva a repensar os Direitos Humanos, a sociedade como um todo e a natureza, a partir dos pressupostos sociais, culturais, materiais e interculturais.

\section{Considerações finais}

Como podemos pensar mais especificamente na complementaridade entre o direito natural (dignidade humana) e as utopias sociais (felicidade)? Esta dúvida com certeza permanecerá. Fato é que precisamos expandir o legado dos direitos naturais de modo a incluir as lutas dos movimentos sociais e alternativos. Temos que lutar pelo reconhecimento dos direitos civis e socioeconômicos também dos outros e pela eliminação a todas as circunstancias nas quais o ser humano é humilhado, desprezado, escravizado e inadequado. Lembrando, que

\begin{tabular}{|l|l|l|l|l|}
\hline Qevista Q Dialectus & Ano 10 & n. 21 & Janeiro - Abril 2021 & p. 176 - 188 \\
\hline
\end{tabular}




\section{DIGNIDADE E UTOPIA NO PENSAMENTO DE ERNST BLOCH}

Paulo Hahn

por inadequação o Bloch entende o desacordo do mundo social existente com a natureza humana. Pois dentro das condições histórico-sociais estabelecidas, o homem não pode desenvolver-se integralmente; ou seja, ele não pode desenvolver as faculdades nele dispostas pela natureza.

Ante estes postulados, a filosofia blochiana contribui para que estas tensões e interações permaneçam indissociáveis - dignidade, felicidade, multiverso, direitos humanos, solidariedade e intersubjetividade -; estabelecendo assim, uma construtiva interlocução, criando "espaços de encontro e resistência a toda forma de dominação [...] e democratizando a utopia e utopizando a democracia" (AÍNSA, 2004, p. 9).

Trata-se de fundamentar a relevância da relação dialética e complementar entre o direito natural e as utopias sociais, entre a dignidade e a felicidade, entre o indivíduo, natureza e coletividade; porém uma coletividade solidaria e intersubjetividade, como uma unidade polifônica de indivíduos em uma direção. O que significa, sobretudo, de que a "verdadeira instituição dos direitos humanos" (BLOCH, 1985, p.13) é possível.

\section{Referências:}

AINSA, Fernando. Espacios de encuentro y mediacion. Sociedad civil, democracia y utopía en América Latina. Montevideo: Nordon, 2004.

BECCHI, Paolo. O princípio da dignidade humana. Aparecido/SP: Editora Santuário, 2013

BLOCH, Ernst. BLOCH, Ernst. Naturrecht und menschliche Würde. Bd. 6. Suhrkamp Taschenbuch Wissenschaft, 555: Frankfurt a. M.: Suhrkamp, 1985.

BLOCH, Ernst. O Princípio Esperança. Vol. 1. Rio de Janeiro: Ed. UERJ: Contraponto, 2005.

BLOCH, Ernst. O Princípio Esperança. Vol. 2. Rio de Janeiro: Ed. UERJ: Contraponto, 2006.

BLOCH, Ernst. O Princípio Esperança. Vol. 3. Rio de Janeiro: Ed. UERJ: Contraponto, 2006.

BLOCH, Ernst. Derecho Natural y Dignidad Humana. Madrid: Editorial Dykinson, 2011.

BLOCH, Ernst. Erbschaft dieser Zeit. Frankfurt a. M.: Suhrkamp,1962.

BLOCH, Ernst. Experimentum Mundi. Frage, Kategorien des Herausbringens, Praxis. Frankfurt a. M.: Suhrkamp,1975.

BLOCH, Ernst. Tübinger Einleitung in die Philosophie. Frankfurt a. M.: Suhrkamp,1970.

\begin{tabular}{|l|l|l|l|l|}
\hline Qevista Dialectus & Ano 10 & n. 21 & Janeiro - Abril 2021 & p. 176 - 188 \\
\hline
\end{tabular}


DIETSCHY, Beat. Gebrochene Gegenwart: Ernst Bloch, Ungleichzeitigkeit und das Geschichtsbild der Moderne. Frankfurt: Vervuert, 1988.

HAHN, Paulo. A "não-simultaneidade" e "multiversum" contra um Totum cultural: uma possível aproximação de Ernst Bloch com a filosofia intercultural. In: Pontes Interculturais. São Leopoldo: Nova Harmonia, 2007, p. 139-149.

HERVADA Xiberta, Javier. Ernst Bloch. Derecho Natural y dignidad humana, in: Anuario de Filosofia del Derecho. Madrid: La editorial del BOE, 1984, págs. 390 a 392.

MAIHOFER, Werner. Rechtstaat und menschliche Würde. Frankfurt a. M. Suhrkamp, 1968. MASCARO, Alysson Leandro Barbate. Utopia e direito - Ernst Bloch e a ontologia jurídica da utopia. São Paulo: Quartier Latin, 2008.

MÜNSTER, Arno. Ernst Bloch. Eine politische Biographie. Darmstadt: WBG, 2004.

PANIKKAR, Raimundo. Paz e interculturalidad: una reflexión filosófica. Barcelona: Herder, 2006.

\begin{tabular}{|l|l|l|l|l|}
\hline Qovista Dialectus & Ano 10 & n. 21 & Janeiro - Abril 2021 & p. 176 - 188 \\
\hline
\end{tabular}

